\title{
Thermography in Breast Cancer Diagnosis
}

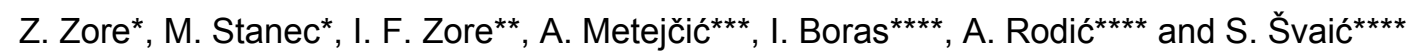 \\ *Department of Oncologic Surgery, Clinical Hospital "Sister of Mercy", Zagreb, Croatia, \\ zore.zvonimir@gmail.com; mstanec@net.hr
}

${ }^{* *}$ Department of Oral Surgery, School of Dental Medicine University of Zagreb, Zagreb, Croatia filipovic@sfzg.hr

\footnotetext{
${ }^{* * * D e p a r t m e n t ~ f o r ~ T r a u m a t o l o g y, ~ S u r g e r y ~ C l i n i c, ~ C l i n i c a l ~ H o s p i t a l ~ " S i s t e r ~ o f ~ M e r c y ", ~ Z a g r e b, ~ C r o a t i a, ~}$ aljosa.matejcic@zg.htnet.hr
}

****University of Zagreb, Faculty of Mechanical Engineering and Naval Architecture, Zagreb, Croatia, ivanka.boras@fsb.hr; alan.rodic@fsb.hr; srecko.svaic@fsb.hr

\begin{abstract}
This study aims to analyse an impact immunohystochemical (IHC) factors have on thermography findings depending on IHC phenotype of invasive breast tumor. Protein HER-2 status, as a prognostic and predictive factor, has so far not been a subject of thermographic tests. According to IHC profile of all parameters on temperature scale, going from the coldest to the warmest tumors group, an impact on measured temperatures was proportionate to an individual and common impact of the analysed IHC factors. According to the results of this study, the tumors that are thermographically warmer have poorer IHC parameters. Thermographically colder tumors could be represented by those with the best as well as by those with the worst prognostic IHC parameters.
\end{abstract}

\section{Introduction}

Infrared thermography (IR) as a diagnostic method used for early detection, diagnostics and prognosis of breast tumors. Malignant tumor is the most important finding that can be detected in a thermogram. The practice had positively confirmed that thermal response is directly proportionate to biological activity of tumor. An intensified blood flow is indicated as hyperthermia and hipervascularity and directly related to the level of biological activity of tumor. Regardless whether this is an issue of metabolism or immunologic reaction, temperature is always increased. The tumor size is not directly related with degree of hyperthermia. Hyperthermia varies, and in extreme cases of inflammatory carcinoma a temperature increase was recorded in absolute value of $6^{\circ} \mathrm{C}$ compared to a normal breast $(2,3)$. Immunohystochemical (IHC) reaction of invasive breast tumors to ER, PR, HER-2 reflects tumor biological aggression, which directly affects the disease prognosis. Earlier thermographic studies have shown that some IHC factors could determine aggression of invasive breast tumor by thermobiological signs. This study intends to analyse an impact on thermography findings of HER-2 status as a prognostic and predictive factor, which has so far not been a subject of thermographic tests combined with other IHC factors, depending on IHC phenotype of an invasive breast tumors.

\section{Patients and methods}

The study was prepared at the Sister of Mercy Clinical Hospital, Oncologic Surgery Department and Pathology Department, in collaboration with licensed IC thermography experts from the University of Zagreb Faculty of 
Mechanical Engineering and Naval Architecture Department of Thermodynamics, Thermal and Process Engineering. The study involved 130 female patients examined during a one-month period in 2011. The patients with indication for surgical treatment of suspected breast changes were pre-operatively examined using thermography. After surgical treatment and obtained patohistological diagnosis (PHD), 75 patients who were diagnosed with invasive breast tumor remained in the study. Thermography was carried out using thermographic system ThermaCAM 2000, under ambulatory conditions, in an air-conditioned $4 \times 3 \mathrm{~m}$ room, and constant humidity and temperature of $22-23^{\circ} \mathrm{C}$. The imaging was carried out with patients in sitting position, their arms on the back of the head, with maximum inspiration, from a distance of $80 \mathrm{~cm}$. A front image was made of thorax with axilla, both in right and left oblique projections.

The patohistological diagnosis contained parameters analysed in the study, which are also routinely determined immunohystochemically for breast carcinoma, i.e. hormone receptors (estrogen and progesterone) and protein HER-2.

To determine expression of estrogen and progesterone receptors and HER-2 in tumor cells of the primary breast carcinoma, immunohystochemical staining was carried out in an automatic DakoAutostainer at room temperature. Prepared tissue slides were treated with primary mice monoclonal ER a antibodies (DAKO; M 7047; 1:50) and PR (DAKO; M 3569; 1:75), according to the manufacturer's protocol, by HRP/DAB method of secondary antibody conjugated with peroxidase and DAB chromogene (Dako Danmark). HER-2 expression determination (Kit HER-2, DAKO; K 5207; ready to use) is done routinely using Hercep Test ${ }^{\circledR}$ which is, according to the manufacturers protocol, a modification of the mentioned IHC method (Dako Denmark). According to the immunohystochemical reaction of breast tumor to estrogen and progesterone receptors, the result is considered negative if reactivity was indicated for less than $10 \%$ tumour cells, namely nucleus. As positive findings for HER-2 were considered those with $3+$ or $2+$, and clearly confirmed by a chromogenic in situ hybridisation (CISH) or, when the $\mathrm{CISH}$ finding is not clear, by fluorescence in situ hybridisation (FISH).

IR image (thermogram), namely the measurement results were analysed using a computer program ThermaCAMResearcher. A "field" analysis tool was used to measure: maximum, minimum and average values and standard deviation of temperature of tumor, entire breast with tumor, on a healthy breast side opposite to that of the tumor, and the entire healthy breast.

Thermographic findings were used for comparison with obtained parameters of IHC findings, showing their impact on temperature data, in line with the characteristics given to a particular group of patients with invasive breast tumor.

A statistical analysis of data was carried out with SPSS program for Windows 17 (SPSS Inc., Chicago, II). The distribution normality was tested with a one-way Kolmogorov-Smirnov test. The statistical analysis included descriptive statistics, Student t-test for dependent and independent samples, and a one-way variance analysis (one-way ANOVA).

\section{Results}

The study included 75 patients with invasive breast tumor, aged 36 to 86 years. Mean age was $64 \pm 11.36$ years. Of total, 30 patients $(40 \%)$ had tumor in right breast and $45(60 \%)$ in left breast. Most patients, 58 , had ductal invasive tumor, 5 patients had lobular invasive tumor, and 12 patients had some other hystological type of tumour: papillar, mucinous, tubular, medullary, malignant filodes or neuroendocrine tumor.

According to the histological grade,13 patients had grade I, 38 grade II, and 22 patients had grade III tumor. Of total number, 50 patients had no positive axillary metastases $(68 \%)$, while 25 patients had positive axillary lymph nodes (32\%). Distant metastases were found in 3 patients $(4 \%)$ only. 
Among all the patients with invasive breast tumor, 56 had estrogen positive receptors (77\%), and $17(23 \%)$ had estrogen negative receptors, 44 patients $(60 \%)$ had positive progesterone receptors, and 29 had negative progesterone receptors (40\%). Altogether 14 patients (19\%) had positive HER-2, and 59 patients (81\%) had negative HER-2. Table 1 shows arithmetic means ( $\mathrm{x}$ ), standard deviations (SD), and minimum and maximum temperatures in tumor site and entire breast with tumor, and in healthy breast side opposite to that of the tumor and in entire healthy breast.

Table 1. Arithmetic means ( $x$ ), standard deviations (SD), and minimum and maximum temperatures in tumor site and entire breast with tumor, and in healthy breast side opposite to that of the tumour and in entire healthy breast.

\begin{tabular}{|c|c|c|}
\hline Variable & $\mathbf{x}$ & SD \\
\hline Maximal temperature - tumor & 35,75 & 1,05 \\
\hline $\begin{array}{l}\text { Maximal temperature opposite side tumor in health } \\
\text { breast }\end{array}$ & 34,92 & 1,36 \\
\hline Average temperature - tumor & 34,96 & 1,16 \\
\hline $\begin{array}{l}\text { Average temperature opposite side tumor in health } \\
\text { breast }\end{array}$ & 34,20 & 1,30 \\
\hline Maximal temperature breast with tumor & 36,09 & 0,94 \\
\hline Maximal temperature health breast & 35,85 & 1,08 \\
\hline Average temperature breast with tumor & 34,39 & 1,51 \\
\hline Average temperature health breast & 33,94 & 1,37 \\
\hline
\end{tabular}

Table 2 shows testing of significance of differences between arithmetic means of temperatures for tumor and the opposite side, as well as for the entire breast with tumor and healthy breast, for maximum measured and average temperatures. A statistically significant difference was recorded in all cases, namely the tumor and the breast with tumor were statistically significantly warmer $(p<0.001)$ than the opposite side.

Table 2. Testing significance of differences between arithmetic means of temperatures measured in healthy and breast with tumor.

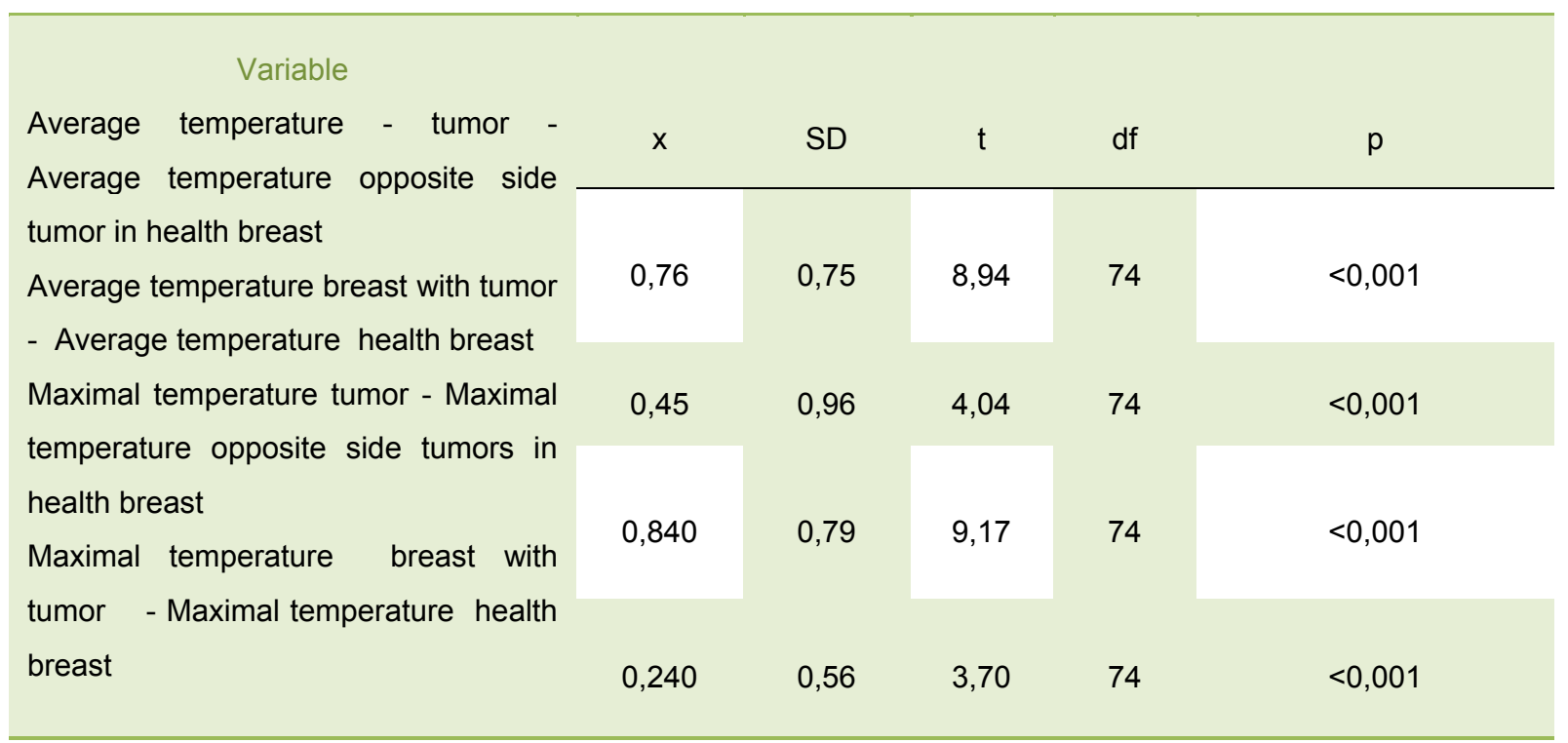


Descriptive statistics and testing significance of differences between measured temperatures depending on tumor positive or negative estrogen receptors is shown in table 3. Levene test indicated equality of variances between positive and negative group, and the degree of freedom was 71 . There were no statistically significant differences $(p>0.05)$ between the patients with positive $(N=56)$ and negative $(N=17)$ tumor receptors for estrogen, with possibility of error of $5 \%$ (i.e. probability of $95 \%$ ).

Table 3 shows that group with ER- has higher maximum and average tumor temperature as compared to the group with ER+. It is also indicated that the group with ER+ has higher maximum and average temperature of the entire breast with tumor as compared to the group with ER-.

Table 3. Testing significance of difference between patients with tumors with positive and negative estrogen receptors (Student $t$-test for independent samples).

\begin{tabular}{|c|c|c|c|c|c|c|}
\hline & ER & $\mathrm{N}$ & $x$ & SD & $\mathrm{t}$ & $p$ \\
\hline \multirow[t]{2}{*}{ Maximal temperature - tumor } & - & 17 & 35,81 & 0,72 & \multirow[t]{2}{*}{0,49} & \multirow[t]{2}{*}{$0,62 \mathrm{NS}$} \\
\hline & + & 56 & 35,67 & 1,09 & & \\
\hline \multirow[t]{2}{*}{ Average temperature - tumor } & - & 17 & 35,03 & 0,75 & \multirow[t]{2}{*}{0,46} & \multirow[t]{2}{*}{$0,65 \mathrm{NS}$} \\
\hline & + & 56 & 34,88 & 1,24 & & \\
\hline \multirow[t]{2}{*}{ Maximal temperature breast with tumor } & - & 17 & 36,02 & 0,67 & \multirow[t]{2}{*}{$-0,18$} & \multirow[t]{2}{*}{$0,86 \mathrm{NS}$} \\
\hline & + & 56 & 36,06 & 0,97 & & \\
\hline \multirow[t]{2}{*}{ Average temperature breast with tumor } & - & 17 & 34,29 & 0,94 & \multirow[t]{2}{*}{$-0,21$} & \multirow[t]{2}{*}{$0,83 \mathrm{NS}$} \\
\hline & + & 56 & 34,38 & 1,66 & & \\
\hline \multirow{2}{*}{$\begin{array}{l}\text { Maximal temperature opposite side tumor } \\
\text { in health breast }\end{array}$} & - & 17 & 35,05 & 0,98 & \multirow[t]{2}{*}{0,64} & \multirow[t]{2}{*}{$0,52 \mathrm{NS}$} \\
\hline & + & 56 & 34,81 & 1,44 & & \\
\hline \multirow{2}{*}{$\begin{array}{l}\text { Average temperature opposite side tumor } \\
\text { in health breast }\end{array}$} & - & 17 & 34,11 & 1,12 & \multirow[t]{2}{*}{$-0,17$} & \multirow[t]{2}{*}{$0,86 \mathrm{NS}$} \\
\hline & + & 56 & 34,17 & 1,34 & & \\
\hline \multirow[t]{2}{*}{ Maximal temperature health breast } & - & 17 & 35,69 & 0,69 & \multirow[t]{2}{*}{$-0,52$} & \multirow[t]{2}{*}{$0,60 \mathrm{NS}$} \\
\hline & + & 56 & 35,85 & 1,15 & & \\
\hline \multirow[t]{2}{*}{ Average temperature health breast } & - & 17 & 33,78 & 1,13 & \multirow[t]{2}{*}{$-0,41$} & \multirow[t]{2}{*}{$0,68 \mathrm{NS}$} \\
\hline & + & 56 & 33,94 & 1,44 & & \\
\hline \multirow[t]{2}{*}{$\begin{array}{l}\text { Difference average temperature tumor and } \\
\text { opposite side }\end{array}$} & - & 17 & 0,92 & 0,78 & \multirow[t]{2}{*}{1,01} & \multirow[t]{2}{*}{$0,31 \mathrm{NS}$} \\
\hline & + & 56 & 0,71 & 0,73 & & \\
\hline \multirow[t]{2}{*}{$\begin{array}{l}\text { Difference average temperature breast } \\
\text { with tumor and health breast }\end{array}$} & - & 17 & 0,51 & 0,43 & \multirow[t]{2}{*}{0,24} & \multirow[t]{2}{*}{$0,81 \mathrm{NS}$} \\
\hline & + & 56 & 0,44 & 1,09 & & \\
\hline
\end{tabular}

Descriptive statistics and testing significance of difference between measured temperatures depending on positive or negative progesterone receptors in tumor is shown in table 4 . Levene test indicated equality of variances between positive and negative group, and the degree of freedom was 71 . The Student t-test for independent samples generally indicated no statistically significant differences $(p>0.05)$ (with possibility of error of $5 \%)$ between the patients with progesterone positive receptor tumors $(\mathrm{N}=44)$ and those with progesterone negative tumor receptors $(\mathrm{N}=29)$. The only statistical significance (with possibility of error of more than 1\%) $(p>0.01)$ was noted for arithmetical means for maximum temperatures and average temperatures of tumors, which were considerably higher for progesterone negative than for progesterone positive tumors $(p<0.05)$. 
Table 4. Testing significance of difference between patients with tumors with positive and negative progesterone receptors (Student $t$-test for independent samples).

\begin{tabular}{|c|c|c|c|c|c|c|}
\hline & PR & $\mathrm{N}$ & $x$ & SD & $\mathrm{t}$ & $p$ \\
\hline \multirow[t]{2}{*}{ Maximal temperature - tumor } & - & 29 & 36,01 & 0,77 & \multirow[t]{2}{*}{2,14} & \multirow[t]{2}{*}{$0,036^{*} \mathrm{~S}$} \\
\hline & + & 44 & 35,51 & 1,11 & & \\
\hline \multirow{2}{*}{ Average temperature - tumor } & - & 29 & 35,31 & 0,84 & \multirow[t]{2}{*}{2,5} & \multirow[t]{2}{*}{$0,015^{*} \mathrm{~S}$} \\
\hline & + & 44 & 34,66 & 1,25 & & \\
\hline \multirow{2}{*}{$\begin{array}{l}\text { Maximal temperature breast with } \\
\text { tumor }\end{array}$} & - & 29 & 36,25 & 0,70 & \multirow[t]{2}{*}{1,55} & \multirow[t]{2}{*}{$0,126 \mathrm{NS}$} \\
\hline & + & 44 & 35,92 & 1,00 & & \\
\hline \multirow{2}{*}{ Average temperature breast with tumor } & - & 29 & 34,65 & 1,01 & \multirow[t]{2}{*}{1,35} & \multirow[t]{2}{*}{$0,18 \mathrm{NS}$} \\
\hline & + & 44 & 34,16 & 1,75 & & \\
\hline \multirow{2}{*}{$\begin{array}{l}\text { Maximal temperature opposite side } \\
\text { tumor in health breast }\end{array}$} & - & 29 & 35,24 & 1,00 & \multirow[t]{2}{*}{1,96} & \multirow[t]{2}{*}{$0,054 \mathrm{NS}$} \\
\hline & + & 44 & 34,63 & 1,49 & & \\
\hline \multirow{2}{*}{$\begin{array}{l}\text { Average temperature opposite side } \\
\text { tumor in health breast }\end{array}$} & - & 29 & 34,42 & 1,13 & \multirow[t]{2}{*}{1,46} & \multirow[t]{2}{*}{$0,15 \mathrm{NS}$} \\
\hline & + & 44 & 33,98 & 1,35 & & \\
\hline \multirow[t]{2}{*}{ Maximal temperature health breast } & - & 29 & 35,98 & 0,72 & \multirow[t]{2}{*}{1,07} & \multirow[t]{2}{*}{$0,29 \mathrm{NS}$} \\
\hline & + & 44 & 35,71 & 1,23 & & \\
\hline \multirow[t]{2}{*}{ Average temperature health breast } & - & 29 & 34,22 & 1,16 & \multirow[t]{2}{*}{1,61} & \multirow[t]{2}{*}{$0,11 \mathrm{NS}$} \\
\hline & + & 44 & 33,70 & 1,47 & & \\
\hline \multirow[t]{2}{*}{$\begin{array}{l}\text { Difference average temperature tumor } \\
\text { and opposite side }\end{array}$} & - & 29 & 0,89 & 0,68 & \multirow[t]{2}{*}{1,22} & \multirow[t]{2}{*}{$0,23 \mathrm{NS}$} \\
\hline & + & 44 & 0,68 & 0,78 & & \\
\hline \multirow[t]{2}{*}{$\begin{array}{l}\text { Difference average temperature breast } \\
\text { with tumor and health breast }\end{array}$} & - & 29 & 0,43 & 0,42 & - & \multirow[t]{2}{*}{$0,89 \mathrm{NS}$} \\
\hline & + & 44 & 0,47 & 1,22 & 0,14 & \\
\hline
\end{tabular}

When significance of difference between arithmetic means of maximum or average temperatures was tested for patients with HER-2 positive and HER-2 negative tumors, the Student t-test for independent samples indicated statistically significant differences $(p<0.05)$ (possibility of error of $5 \%$, i.e. probability $95 \%$ ) between the patients with HER-2 positive tumors $(\mathrm{N}=14)$ and the patients with HER-2 negative tumors $(\mathrm{N}=59)$ for the following variables: maximum tumor temperature, average tumor temperature, maximum temperature of the entire breast with tumor and difference between an average temperature of tumor and the side opposite to that of the tumor. The arithmetic means of maximum and average temperature of tumors, arithmetic means of maximum temperatures of breast with tumors, and the difference between the average temperature of tumor and the side opposite to that of the tumor were significantly higher for HER-2 positive than for HER-2 negative tumors $(p<0.05)$. A variable "average temperature of entire breast with tumor" showed no statistically significant difference between HER-2 positive and negative tumors, but arithmetic means were higher for HER-2 positive tumors, and would be significantly higher with possibility of error of $11 \%(p=0.11)$. Descriptive statistics and testing of significance of difference between measured temperatures depending on positive or negative HER-2 in tumor is shown in table 5. Levene test indicated equality of variances between HER-2 positive and negative group, therefore the degree of freedom was 71. 
Table 5. Testing significance of difference between patients with tumors with positive and negative HER-2 (Student t-test for independent samples).

\begin{tabular}{|c|c|c|c|c|c|c|}
\hline & HER-2 & $\mathrm{N}$ & $\mathrm{x}$ & SD & $\mathrm{t}$ & $p$ \\
\hline \multirow[t]{2}{*}{ Maximal temperature - tumor } & - & 59 & 35,60 & 0,97 & \multirow[t]{2}{*}{$-1,98$} & \multirow[t]{2}{*}{$0,048 * S$} \\
\hline & + & 14 & 36,17 & 1,10 & & \\
\hline \multirow[t]{2}{*}{ Average temperature - tumor } & - & 59 & 34,78 & 1,15 & \multirow[t]{2}{*}{$-2,15$} & \multirow[t]{2}{*}{$0,035^{*} \mathrm{~S}$} \\
\hline & + & 14 & 35,49 & 0,97 & & \\
\hline \multirow{2}{*}{$\begin{array}{l}\text { Maximal temperature breast with } \\
\text { tumor }\end{array}$} & - & 59 & 35,92 & 0,91 & \multirow[t]{2}{*}{$-2,60$} & \multirow[t]{2}{*}{$0,012^{*} \mathrm{~S}$} \\
\hline & + & 14 & 36,59 & 0,68 & & \\
\hline \multirow{2}{*}{$\begin{array}{l}\text { Average temperature breast with } \\
\text { tumor }\end{array}$} & - & 59 & 34,22 & 1,60 & \multirow[t]{2}{*}{$-1,60$} & \multirow[t]{2}{*}{$0,11 \mathrm{NS}$} \\
\hline & + & 14 & 34,94 & 0,89 & & \\
\hline \multirow{2}{*}{$\begin{array}{l}\text { Maximal temperature opposite side } \\
\text { tumor in health breast }\end{array}$} & - & 59 & 34,80 & 1,36 & \multirow[t]{2}{*}{$-0,91$} & \multirow[t]{2}{*}{$0,365 \mathrm{NS}$} \\
\hline & + & 14 & 35,16 & 1,28 & & \\
\hline \multirow{2}{*}{$\begin{array}{l}\text { Average temperature opposite side } \\
\text { tumor in health breast }\end{array}$} & - & 59 & 34,08 & 1,31 & \multirow[t]{2}{*}{$-1,08$} & \multirow[t]{2}{*}{$0,284 \mathrm{NS}$} \\
\hline & + & 14 & 34,49 & 1,15 & & \\
\hline \multirow[t]{2}{*}{ Maximal temperature health breast } & - & 59 & 35,68 & 1,09 & \multirow[t]{2}{*}{$-2,23$} & \multirow[t]{2}{*}{$0,029 * S$} \\
\hline & + & 14 & 36,36 & 0,74 & & \\
\hline \multirow[t]{2}{*}{ Average temperature health breast } & - & 59 & 33,76 & 1,42 & \multirow[t]{2}{*}{$-1,195$} & \multirow[t]{2}{*}{$0,06 \mathrm{NS}$} \\
\hline & + & 14 & 34,52 & 0,92 & & \\
\hline \multirow[t]{2}{*}{$\begin{array}{l}\text { Difference average temperature } \\
\text { tumor and opposite side }\end{array}$} & - & 59 & 0,71 & 0,79 & \multirow[t]{2}{*}{$-1,978$} & \multirow[t]{2}{*}{$0,048 * S$} \\
\hline & + & 14 & 1,01 & 0,44 & & \\
\hline \multirow[t]{2}{*}{$\begin{array}{l}\text { Difference average temperature } \\
\text { breast with tumor and health breast }\end{array}$} & - & 59 & 0,46 & 1,08 & \multirow[t]{2}{*}{0,172} & \multirow[t]{2}{*}{$0,86 \mathrm{NS}$} \\
\hline & + & 14 & 0,41 & 0,22 & & \\
\hline
\end{tabular}

According to a combination of analysed IHC factors of invasive tumors in all patients in this study, different groups of patients with the same IHC tumor phenotype were created. They formed temperature scales starting from a group of patients with the lowest recorded average temperature of the tumor itself and breast with tumor, going towards groups with higher average temperatures, and ultimately to a group with the highest recorded average temperature of the tumor and the breast with tumor. The lowest average temperature was recorded in the group of patients with positive hormone receptors and negative HER-2. The highest average temperature of the tumor and the breast with tumor was recorded in the group of patients with ER+, PR-, HER+ ( table 6). 
Table 6. Temperature scale of arithmetic means of temperatures measured in tumor and in breast with tumor depending on immunohystochemical phenotype of tumor (ER, PR and HER-2).

\begin{tabular}{|c|c|c|c|c|c|c|c|}
\hline $\mathbf{n}$ & ER & PR & HER-2 & $\begin{array}{c}\text { Average } \\
\text { tumor } \\
\text { temp }\end{array}$ & $\begin{array}{c}\text { Average } \\
\text { temp } \\
\text { breast + tm }\end{array}$ & $\begin{array}{c}\text { Average } \\
\left.\text { size tm } \mathbf{( m m}^{3}\right)\end{array}$ & $\begin{array}{c}\text { Average } \\
\text { grade } \\
\text { tumor }\end{array}$ \\
\hline $\mathbf{4 1}$ & + & + & - & $\mathbf{3 4 , 5 8}$ & 34,09 & 16254,00 & $\mathbf{1 , 8 5}$ \\
\hline $\mathbf{1 1}$ & - & - & - & 34,95 & 34,15 & 5418,27 & 2,55 \\
\hline $\mathbf{6}$ & - & - & + & 35,18 & 34,53 & 18577,00 & 2,83 \\
\hline $\mathbf{7}$ & + & - & - & 35,70 & 35,11 & 3396,86 & 2,29 \\
\hline $\mathbf{5}$ & + & - & + & 35,74 & 35,24 & 8863,20 & 2,40 \\
\hline
\end{tabular}

Table 7 shows testing significance of difference between average tumor temperatures between $(E R+, P R+, H E R-$ 2-) tumors and (ER+, PR-, HER-2+) tumors. As shown, the average temperature of ER+, PR+, HER-2- tumors is statistically significantly lower $(p<0.05)$ than for $E R+, P R-$, HER-2+ tumors.

Table7. Testing significance of difference between average tumor temperatures for (ER+, $P R+, H E R-2-)$ tumors and (ER+, PR-, HER-2+) tumors.

\begin{tabular}{|c|c|c|}
\hline Phenotype of tumor & ER+,PR+,HER-2- & ER+,PR-,HER-2+ \\
\hline Aritmetic mean & 34,58 & 35,74 \\
\hline Variance & 1,46 & 0,988 \\
\hline $\mathbf{n}$ & 41 & 5 \\
\hline df & 44 & \\
\hline $\mathbf{t}$ & $-2,06$ & \\
\hline$P(T<=t))$ one-way & $0,02^{*} S$ & \\
\hline Critical $t$ test for sigle & 1,68 & \\
\hline
\end{tabular}




\section{Discussion}

All previous thermographic studies have indicated that larger tumors with metastases in regional lymph nodes as compared to smaller tumors, fast proliferating as compared to slowly proliferating, and less differentiated as compared to well differentiated, all have evidently more pathological thermobiological indicators, which is a characteristic of more aggressive invasive tumors $(4,5,6)$. It has also been observed that more aggressive invasive tumors belong among the so called "warmer tumors" according to their thermographic findings, and that they directly affect shorter disease-free period and total survival of patients as compared to the so called "colder tumors" $(1,8,10)$. Clinical value of IR thermography as a prognostic factor in patients with invasive breast tumors has in all previous thermographic studies been evaluated based on individual impact of clinical, patohistological and some IHC tumor parameters, namely based on size and number of their thermobiological pathological signs. The fact that during their aggressive growth invasive breast tumors cause an increase in temperature which is reflected on the body surface (skin) and which can be measured by IR thermography was confirmed by the first thermography findings within this study. Maximum and average temperature of both tumor and the entire affected breast was statistically significantly higher than maximum and average temperature of the side opposite to that of the tumor on healthy breast and entire healthy breast in all patients participating in this study.

An analysis of the hormone receptor status in obtained findings show that ER- tumors had higher maximum and average temperature compared to ER+ tumors. It was also observed that ER- tumors had lower impact on warming of the entire breast, and that maximum and average temperature of the affected breast was higher in ER+ tumors. No statistically significant difference was determined in hormone receptor status between patients with ER+ and ER- tumors as regards measured temperatures.

The obtained results on ER impact on thermographic findings from this study are similar to the results of the majority of earlier published thermographic studies. Only Sterns' thermographic study determined that ER- impact on thermographic findings is greater than ER+ impact $(7,9,10)$.

As regards impact of the PR receptor status on thermographic findings, it is obvious that PR-tumors, compared to PR+ tumors, had a statistically significant impact in two temperature findings: maximum and average tumor temperature. Other findings also suggest a trend of PR- tumors having higher impact than PR+ tumors to maximum and average temperature of the entire breast with tumor, but the difference is not statistically significant.

Other significant thermographic research, the results of which are referred to in this study, found no difference between progesterone receptors on thermographic findings $(7,9,10)$.

So far, no thermographic research has published results on impact the HER-2 have on thermographic findings of patients with invasive tumors. Results of this study point to the statistically significant impact of HER-2+ as compared to HER-2-in several temperature findings: for maximum and average tumor temperature, maximum and average temperature of breast with tumor, difference between an average tumor temperature and the side on a healthy breast opposite to that of the tumor. The increased temperature trend in HER-2 + tumors is also indicated in all other temperature findings and in healthy breast. The findings clearly indicate that HER+ status has the highest impact on all temperature measurement findings.

According to a combination of analysed IHC factors of invasive tumors in all patients in this study, different groups of patients with the same IHC tumor phenotype were created. They formed temperature scales starting from a group of patients with the lowest recorded average temperature of the tumor itself and breast with tumor, going towards groups with higher average temperatures, and ultimately to a group with the highest recorded average temperature of the tumor and the breast with tumor. The lowest average temperature was recorded in the group of patients with positive hormone receptors and negative HER-2. The highest average temperature of the tumor and the breast with tumor was recorded in the group of patients with ER+, PR-, HER+. 
The analysis of the group of patients with the so called "cold" tumors shows presence of all IHC parameters that in previous analyses had the least impact on the thermographic findings, namely on average temperature of the tumor and the breast with tumor.

Unlike this group, the analysis of the group of patients with the so called "warmest" tumors shows presence of all IHC parameters that in previous analyses had the highest and/or statistically significant impact on the thermographic findings, namely on average temperature of the tumor and the breast with tumor.

Testing significance of difference between an average temperature of the tumor and breast with tumor in patients with the coldest invasive tumors (ER+, PR+, HER2-) and the patients with the warmest invasive tumors (ER+, PRHER2+) shows that the group with cold tumors has a statistically significantly lower average temperature of the tumor and the breast with tumor.

\section{Conclusion}

The results of the study lead to the following conclusions:

It was shown that positive HER-2 in five temperature findings, and PR negative receptors in two temperature findings, had the largest individual impact of IHC factors on thermographic findings.

According to the IHC profile of all parameters on the temperature scale, from the group with the coldest to the group with the warmest tumors, the impact on measured temperature was proportionate to an individual and combined impact of the analysed IHC factors.

According to the thermographic findings, the colder tumors could represent a group with the best IHC prognostic parameters. They could also represent a group with the worst IHC prognostic parameters, which is contrary to the observations from the thermographic research conducted so far.

According to the thermographic findings for other groups on the temperature scale, the tumor warmth scale or gradation corresponds with the IHC prognostic factors where "warmer" tumor means poorer prognostic parameters, which is in line with the observations from other thermographic research.

According to the results of this study, prognostic value of thermography in clinical use would be that thermographically warmer tumors could be said to have poor prognosis. For thermographically colder tumors, the difference between the best and worst prognosis group will be determined by clinical, patohistological and IHC parameters.

\section{Literature}

1. Amalric D., Giraud D., Altschule C., Spitalier J.M.," Value and interest of dynamic telethermography in detection of breast cancer“. Acta Thermographica, vol. 1, pp. 130-136, 1976.

2. Anbar M., "Breast Cancer". In: Quantitative Dynamic Telethermometry in Medical Diagnosis and Mamagement. CRC Press, Ann Arbor Mich, pp. 84-91,1984.

3. Anbar M., "Clinical thermal imaging today". Engineering Med Biology Magaz IEEE, vol.7, pp. 25-33, 1998.

4. Dilhuydy MH., Le Treut A., Durand M., Avril A., Lagarde C., „The importance of thermography in the prognostic evaluation of breast cancers“. Acta Thermographica, vol.3, pp.130-136, 1978.

5. Fournier VD., Kubli F., Klapp J., Weber E., Schneider-Affeld F.," Infra-red thermography and breast cancer doubling time“. Acta Thermografica, vol.3, pp.107-11,1978.

6. Gros D., Gautherie M., Warter F.," Thermografic prognosis of treated breast cancers“. Acta Thermographica, vol. 6, pp. 107-14, 1981. 
7. Head NY., Wang F., Elliott RL.," Breast thermography is a noninvasive prognostic procedure predicts tumor growth rate in breast cancer patients". Ann N Y Acad Sci, vol.30, pp. 153,1993

8. Isard HJ., Sweitzer CJ., Edelstein GR.," Breast thermography: a prognostic indicator for breast cancer survival". Cancer, vol. 5, pp. 484-8,1998.

9. Shozo O., Shigemitsu T., Kenjiro A., Hisashi U.," Prognostic value of thermografical findings in patients with primary breast cancer". Breast Cancer Research and Treatment, vol.7, pp. 213-20, 2002.

10. Sterns EE., Zee B., Sen Gupta J., Saunders FW.," Thermography: Its relation to pathologic characteristics, vascularity, proliferative rate and survival of patients with invasive ductal carcinoma of the breast". Cancer, vol. 77, pp. 1324-8, 1996. 